\title{
$\mathrm{CRP}$ 시스템의 피팅수명 \\ 김창현*, 남형철*, 권순만
}

(논문접수일 2011. 11. 03, 수정일 2011. 12. 05, 심사완료일 2011. 12. 07)

\section{Pitting Life of CRP System}

\author{
Chang-Hyun Kim*, Hyoungchul Nam*, Soon-Man Kwon ${ }^{+}$
}

\begin{abstract}
Cam rack pinion (CRP) system which consists of cam rack and roller pinion transforms the rotation motion into linear one. The roller pinion has the plurality of rollers and meshes with its conjugated cam rack. The exact tooth profile of the cam rack and the non-undercut condition to satisfy the required performance have been proposed by introducing the profile shift coefficient. The load stress factors are investigated by varying the shape design parameters to predict the gear surface fatigue limit which is strongly related to the gear noise and vibration at the contact patch. The results show that the pitting life can be extended significantly by increasing the profile shift coefficient.
\end{abstract}

Key Words : Cam rack pinion(캠 랙 피니언), Cam rack(캠 랙), Roller pinion(롤러 피니언), Profile shift coefficient(전위계수), Load stress factor(하중응력계수), Pitting life(피팅수명)

\section{NOMENCLATURE}

$C_{r} \quad:$ Roller diameter coefficient

$e \quad:$ Profile shift coefficient

$E^{*} / 2$ : Equivalent elastic modulus

$F_{i} \quad$ : Contact force between the $i$-th roller and the cam rack

$K_{i} \quad$ : Load-stress factor

$l_{i} \quad:$ Moment arm

$m$ : Module

$n$ : No. of initial contact position

$N$ : No. of roller pinion teeth

$N_{p} \quad$ : Pitting life cycles

$p_{H} \quad$ : Hertzian contact stress

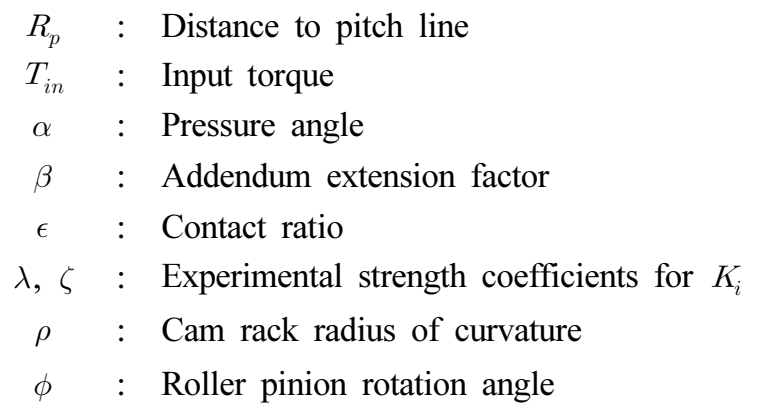

\section{1. 서 론}

대표적 직선이송장치인 랙 피니언(rack pinion) 시스템은 구 조가 간단하고 가격이 저렴한 장점이 있지만, 정밀도가 볼 스크 
류(ball screw)와 리니어 모터(linear motor)에 비해 떨어지는 단점이 있다. 이에 최근 백래시(backlash)를 없애 정밀도가 향 상되고, 원활한 구름접촉으로 마멸에도 강한 직선 이송형 롤러 기어 메커니즘(linear type roller gear mechanism)에 대한 연 구가 주목받고 있다.

$\mathrm{RGM}$ 직선이송장치는 Fig. 1과 같이 랙을 롤러나 핀으로 대 체한 RRP(roller rack pinion) 시스템과 피니언을 롤러나 핀으 로 대체한 $\mathrm{CRP}$ (cam rack pinion) 시스템으로 구분한다. 최근 Gonzalez와 Angeles $^{(1)}$, Chablat와 Angeles ${ }^{(2)}$ 는 캠 피니언 잇 수가 하나인 특수한 형태의 RRP 시스템에 대한 연구를 수행하 여 독특한 직선이송장치인 "Slide-O- Cam”(Fig. 2 참조)을 제 안하였다. 또한 국내에서는 함성훈 등(3)이 RRP 시스템의 최적 치형에 대한 연구를 통해 인벌루트 오프셋 치형을 제시한 바 있다. CRP 시스템은 현재 일본의 Kamo Seiko사에서 자체 개 발 $^{(4)}$ 하여 독점 공급하고 있고, 2005년 미국 Nexen사로의 기술 이전을 통하여 북미시장을 선점하고 있는 실정이다.

$\mathrm{RGM}$ 직선이송장치의 치형설계에 관한 사항과 이를 활용한 연구가 아직까지 많지 않고, 일부 공개된 특허를 기반으로 설계 된 치형을 분석한 결과 치선역(addendum)과 치저역(dedendum) 을 두 곡선으로 연결한 합성치형이 주를 이루고 있어 완벽한 설계로 보기 어렵다.

또한 $\mathrm{RGM}$ 직선이송장치도 접촉상태에서 항시 운전되기 때

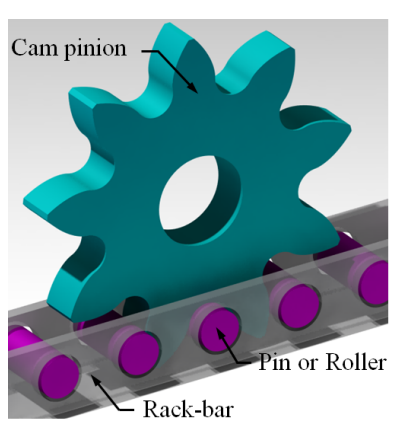

RRP system

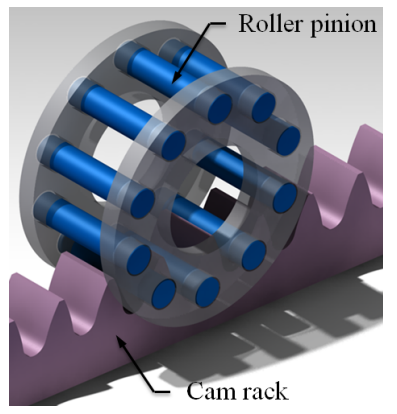

CRP system
Fig. 1 RRP and CRP system

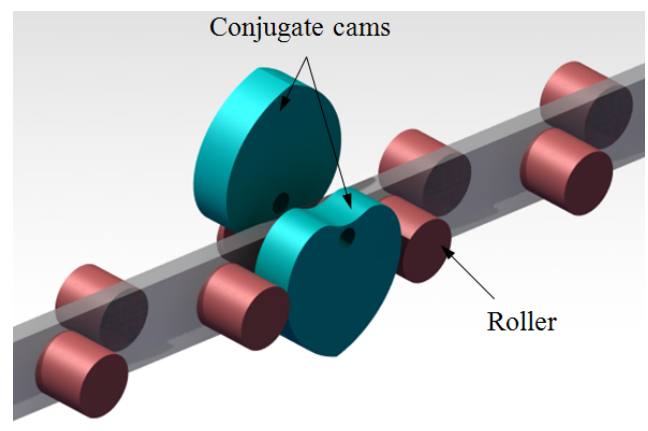

Fig. 2 "Slide-O-Cam" system
문에 반드시 압축응력에 따른 재료적 피로현상을 고려해야 한 다. 특히 기어가 회전함에 있어 하중의 주기적인 변화(Fig. 9 참 조)는 표면 피팅(surface pitting)을 유발하는 주요 원인으로 알 려져 있다. 이에 표면피팅 현상을 규명하기 위해 다양한 접근을 통한 수 많은 연구들이 현재까지 수행되어 왔으나, 피팅기구를 온전히 설명할 수 있는 이론을 찾기는 어려운 실정이다.

$\mathrm{RGM}$ 직선이송장치에 대해서는 Ikejo 등 ${ }^{(5)}$ 과 Nagamura 등 (6)이 각각 합성치형과 전위치형을 갖는 RRP 시스템의 내구시 험을 통하여 전위치형이 합성치형보다 내구성이 우월함을 보 인 바 있다. 함성훈 등 ${ }^{(3)}$ 도 RRP 시스템의 굽힘강도와 면압강도 해석법을 제시했지만 접촉력을 결정하는 방법에 있어 접촉하 는 모든 이를 기준으로 유효 접촉력을 정확하게 산출하지 못했 다. 또한 대부분의 RGM 직선이송장치 연구가 RRP 시스템에 국한되어 있고 $\mathrm{CRP}$ 시스템에 대한 연구는 거의 전무한 상태이다.

이에 본 논문에서는 CRP 시스템에 대해 전위(profile shift) 를 고려한 캠 랙의 엄밀치형을 이용하여 접촉하는 모든 치의 접촉 력을 결정하고, Morrison ${ }^{(7)}$ 의 하중응력계수(load stress factor)를 기반으로 이론적 피팅수명을 예측함으로써 새로운 직선이송장 치로서의 CRP 시스템의 내구성 향상에 기여하고자 한다.

\section{2. 캠 랙 치형}

$\mathrm{CRP}$ 시스템의 형상 설계제원은 롤러 피니언의 롤러 개수 $(N)$, 모듈 $(m)$, 전위계수 $(e)$, 롤러 직경계수 $\left(C_{r}\right)$ 그리고 기어 치선의 높이를 결정하는 치선연장계수 $(\beta)$ 로 구성된다.

Fig. 3에서와 같이 $S_{2 t}$-좌표계에서의 캠 랙 치형 $\left({ }^{2 t} C\right)$ 은 기어 치형 창성의 기본법칙인 Camus의 정리 ${ }^{(8)}$ 와 동차 좌표변환 행 렬을 이용하여 다음과 같이 결정할 수 있다.

$$
{ }^{2 t} C=M_{2 t, 3 f}{ }^{3 f} C
$$

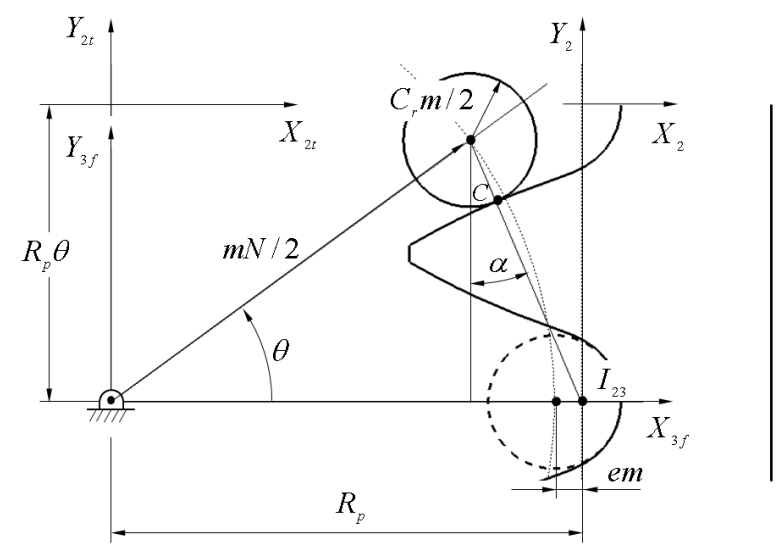

Fig. 3 Schematic for cam rack profile design 
여기서 $M_{2 t, 3 f}$ 는 $S_{3 f}$ 좌표계에서 $S_{2 t}$ 좌표계로의 변환행렬을 나타내고, ${ }^{3 f} C$ 는 고정좌표계 $\left(S_{3 f}\right)$ 에 대한 접촉점의 좌표를 나 타내고 다음과 같다.

$$
{ }^{3 f} C=\left[\begin{array}{c}
\frac{m}{2}\left(N \cos \theta+C_{r} \sin \alpha\right) \\
\frac{m}{2}\left(N \sin \theta-C_{r} \cos \alpha\right) \\
0 \\
1
\end{array}\right]
$$

그리고 $\alpha$ 는 압력각(pressure angle)을 의미한다.

캠 랙의 곡률반경 $(\rho)$ 은 식 (1)의 형상 좌표가 매개변수형으 로 주어지기 때문에 매개변수 곡률 식을 이용하여 다음과 같이 결정할 수 있다.

$$
\rho / m=\frac{N}{2} \frac{\left(\mu^{2}+1-2 \mu \cos \theta\right)^{3 / 2}}{1-\mu \cos \theta}-\frac{C_{r}}{2}
$$

\section{여기서 $\mu=1+2 e / N$ 이다.}

캠 또는 기어형상 설계 시 치 꼬임으로 인한 언더컷(undercut) 을 회피하기 위해 볼록 치형에서의 식 (3)의 곡률반경 값이 음 의 값을 갖지 않도록 롤러 직경계수 최대 값을 다음과 같이 결 정할 수 있다.

$$
\left(C_{r}\right)_{\max }=6 \sqrt{3\left(e^{2}+N e\right)}
$$

하지만 이에 앞서 롤러 피니언 롤러들 사이의 기하학적인 관 계를 고려하여 다음의 롤러 직경계수 최대 값 점검이 먼저 선행 되어야 한다.

$$
\left(C_{r}\right)_{g}=N \sin (\pi / N)
$$

\section{3. 피팅 수명}

피팅 수명 평가를 위한 많은 연구중 Morrison ${ }^{(7)}$ 은 24년간 재 료의 표면피로에 대한 실험적 연구를 실시하여 피팅수명 평가 를 위한 다음의 S-N선도 평가 식을 제안하였다.

$$
N_{p}=10 E\left(\zeta-\lambda \log _{10} \mathrm{~K}_{i}\right)
$$

여기서 $\lambda$ 및 $\zeta$ 는 실험적 강도계수를, $K_{i}$ 는 $i$-번째 롤러의 하중응력계수를 나타내고 그 정의는 다음과 같다.

$$
K_{i}=\frac{F_{i}}{R_{i}^{*} L}
$$

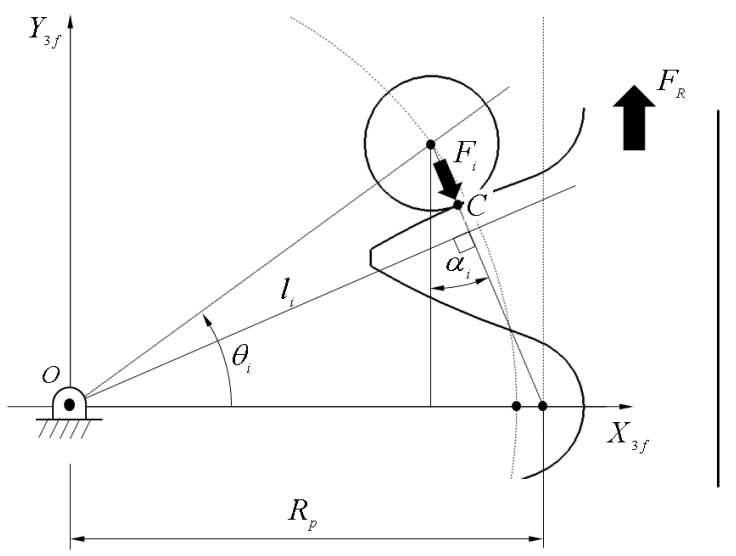

Fig. 4 Schematic for contact force determination

이 때, $R_{i}^{*}$ 는 $i$-번째 롤러 피니언과 캠 랙의 접촉점에서의 등 가 곡률반경이고, $L$ 은 치폭을 의미한다. 또 $i$-번째 롤러와의 접 촉력 $F_{i}$ 는 Fig. 4 와 같이 캠 랙의 이송력 $F_{R}$ 에 의해 롤러 피니 언이 초기 위치에서 $\theta_{i}$ 만큼 회전한 상태에서 변형을 고려한 부 정정 문제 접근 ${ }^{(9,10)}$ 을 이용하여 다음과 같이 결정할 수 있다.

$$
F_{i}=\frac{T_{i n} l_{i}}{\sum_{j=1}^{n} l_{j}^{2}}, \quad(i=1,2,3, \cdots, n)
$$

여기서 $T_{i n}=F_{R} R_{p}$ 이고 $l_{i}$ 는 모멘트 암, $n$ 은 캠 랙과 롤러간 의 초기 접촉개소를 의미하고 각각은 다음과 같다.

$$
\begin{aligned}
& l_{i}=\left\{\begin{array}{cc}
R_{p} \cos \alpha_{i} & \left(0 \leq \alpha_{i}<\frac{\pi}{2}\right) \\
0 & \left(\frac{\pi}{2} \leq \alpha_{i}<\pi\right)
\end{array}\right. \\
& n=2[\beta]+1
\end{aligned}
$$

여기서 [ ] 는 바닥함수(floor function)를 의미한다.

캠 랙과 롤러가 초기 $n$ 개의 접촉위치에서 중앙에 있는 롤러 를 $n_{c}$-번째 롤러라고 정의하면, 이를 기준으로 각 롤러의 회전 각 $\theta_{i}$ 는 아래와 같이 정의할 수 있다.

$$
\theta_{i}=\left(n_{c}-i\right) \theta_{p}+\phi
$$

여기서 $\phi$ 는 접촉이 유지되고 힘이 작용하는 구간까지의 롤 러 피니언 회전각을 의미하고, $\theta_{p}$ 는 피치 회전각을 의미한다.

Talbourdet $^{(11)}$ 는 광범위한 시험에서 압축응력이 Hertz 식으 로 예측한 값과 일치함을 발견하였다. 따라서 $i$-번째 롤러와의 접촉점에서 Hertz 접촉응력은 하중응력계수를 이용하여 다음 과 같이 결정할 수 있다. 
$p_{H}=\sqrt{\frac{K_{i} E^{*}}{2 \pi}}$

여기서 $E^{*} / 2$ 는 등가 탄성계수이다.

\section{4. 결과 분석}

$\mathrm{CRP}$ 시스템의 접촉력 및 하중응력계수 특성을 고찰하기 위 해 Table 1과 같은 형상설계제원을 구성하였다. 여기서 전위계 수는 $0.05,0.1,0.2$ 의 3 가지의 경우에 대해 값을 점차 변화시키 며 그 결과를 고찰하고자 하였고, 치선연장계수 $(\beta)$ 는 물림률 $(\epsilon=3-2 / \beta, 1 \leq \beta<2) 1.8$ 을 고려하여 1.67로 설정하였다. Table 2 는 해석에 필요한 제원으로 일반적인 탄소강에 대한 물 성과 롤러 피니언 회전수 $120 \mathrm{rpm}$ 에서의 허용토크 $150 \mathrm{~N} \cdot \mathrm{m}$ 를 기준으로 랙 이송력 $F_{R}$ 을 $2600 \mathrm{~N}$ 으로 설정하였다.

Fig. 5는 전위계수 $e=0.05$ 로 설정하여 설계된 $\mathrm{CRP}$ 시스템 의 한 초기 접촉형상을 나타내고 있다. 이 때, 캠 랙 이송 시 물림 이탈이 빠른 시간 순서로 롤러들의 접촉번호를 지정하였 고, Table 1 의 설계제원을 기준으로 초기 3 개소의 접촉을 볼 수 있다. 항시 최소 2 개소 이상 접촉을 유지하고, 경우에 따라 5 개소, 7 개소 등으로 다접촉이 가능하므로 정-역 방향의 역회 전이 발생하지 않아 백래시가 거의 없다는 장점을 확인할 수 있다.

Fig. 6은 전위계수에 따른 캠 랙 형상의 변화를 나타내고 있 다. 롤러 피니언 위치반경을 기준으로 전위계수가 증가함에 따 라 치선의 폭과 치의 높이는 감소되고, 치저의 폭은 미세하게

Table 1 Shape design parameters for CRP system

\begin{tabular}{l|c}
\hline \hline Design parameters & Values \\
\hline Module, $m$ & $9.5(\mathrm{~mm})$ \\
\hline No. of roller teeth, $N$ & 12 \\
\hline Roller diameter coefficient, $C_{r}$ & 1.6842 \\
\hline Profile shift coefficient, $e$ & $0.05,0.1,0.2$ \\
\hline Addendum extension factor, $\beta$ & 1.67 \\
\hline
\end{tabular}

Table 2 Analysis parameters of CRP system

\begin{tabular}{l|c|c}
\hline \hline \multicolumn{2}{l|}{ Analysis parameters } & Values \\
\hline \multicolumn{2}{l}{ Rack actuating force, $F_{R}$} & $2600(\mathrm{~N})$ \\
\hline \multicolumn{2}{l|}{ Cam rack width, $L$} & $27(\mathrm{~mm})$ \\
\hline \multirow{2}{*}{ Modulus of elasticity } & $E_{C}$ & $200(\mathrm{GPa})$ \\
\cline { 2 - 3 } & $E_{R}$ & $200(\mathrm{GPa})$ \\
\hline \multirow{2}{*}{ Poisson's ratio } & $\nu_{C}$ & 0.29 \\
\cline { 2 - 3 } & $\nu_{R}$ & 0.29 \\
\hline
\end{tabular}

증가되는 것을 관찰할 수 있다.

일반적인 인벌루트 기어 치형과는 달리 CRP 시스템의 압력각 은 가변적이다. 이러한 변화를 전위계수에 따라 Fig. 7에 도시하

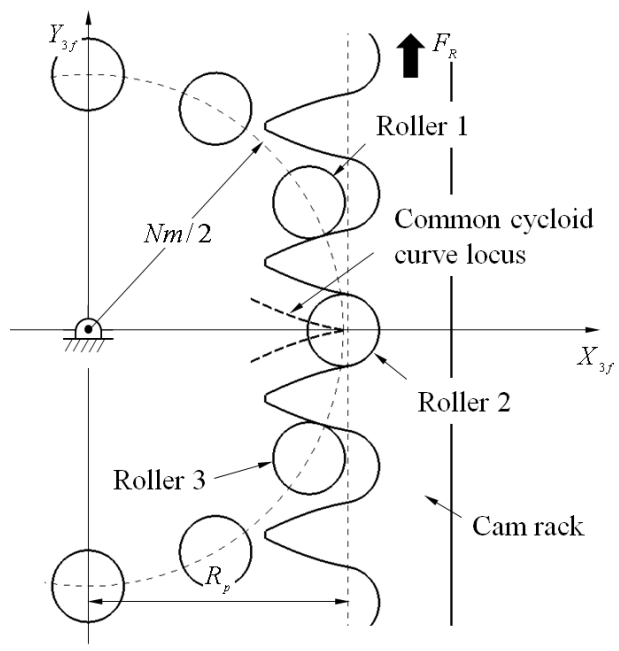

Fig. 5 Designed CRP system for $e=0.05$

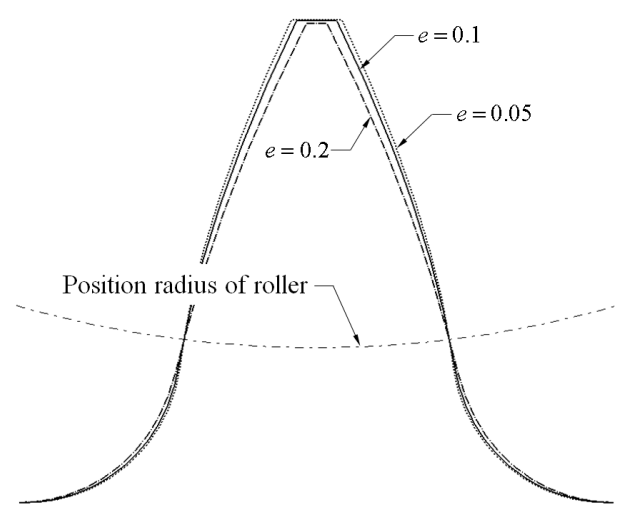

Fig. 6 Cam rack profile variations with $e(\epsilon=1.8)$

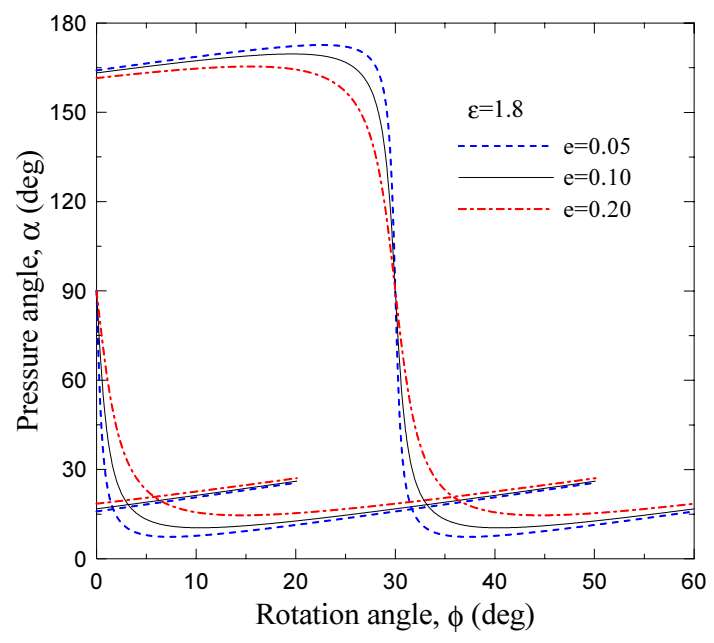

Fig. 7 Pressure angles with the variation of $e$ 
였다. 전위계수가 증가함에 따라 유효 접촉구간 $\left(0 \leq \alpha_{i}<\pi / 2\right)$ 에서의 압력각도 증가함을 확인할 수 있다.

Fig. 8은 접촉에 참여하고 있는 롤러 1, 2, 3(Fig. 5 참조)과 접촉하는 캠 랙의 곡률반경을 전위계수 변화에 따라 나타내고 있다. 곡률반경 역시 전위계수가 증가함에 따라 증가함을 확인 할 수 있고, 이는 식 (7)과 (12)에서 유추할 수 있듯이 하중응력 계수와 접촉응력 결과 값을 낮추는 긍정적 영향을 기대할 수 있다.

Fig. 9는 전위계수 0.05 일 때 해석하고자 하는 유효 접촉력 구간에서의 롤러들의 접촉력 변화를 나타낸다. 롤러 1(Fig. 5 참조)이 접촉 이탈되기 전 까지 두 쌍의 치가 하중을 분담하고 이후 한 쌍의 치(롤러 2)가 모든 하중을 전담하다 피치각 이후 부터 다시 두 쌍의 치가 하중을 분담하는 주기적 변화를 확인할 수 있다. 이러한 하중의 급격한 변화는 표면 피팅에 관여하는 주된 인자로 알려져 있다. 이에 한 쌍의 치가 하중을 전담하는

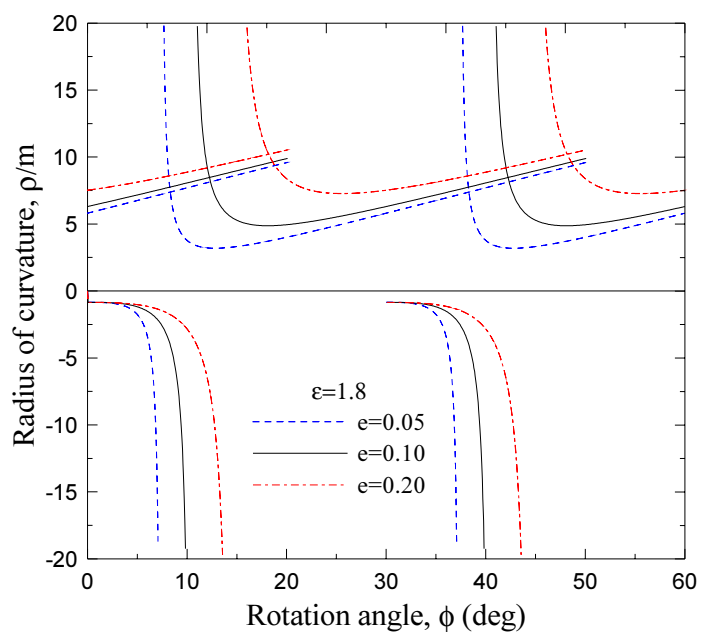

Fig. 8 Radius of curvature variation with $e$

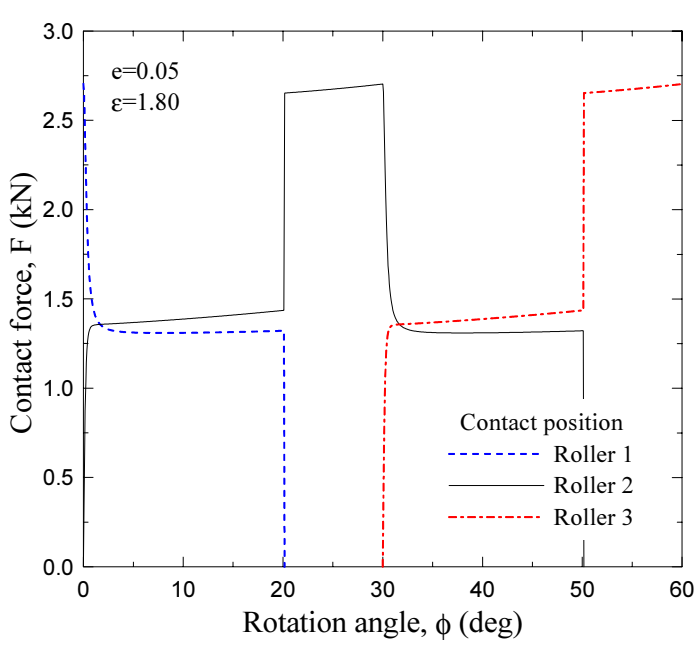

Fig. 9 Distribution of contact forces for $e=\mathbf{0 . 0 5}$
구간을 변화시켜 그 결과를 고찰하기 위해 전위계수를 0.05 로 고정하고 물림률을 $1.6,1.7,1.8$ 로 달리하면서 롤러 2 에 대한 하중의 변화를 Fig. 10에 나타내었다. 그림에서 볼 수 있듯이 물림률이 크면 롤러 1 이 이탈되는 시점이 연장되므로 한 쌍의 치가 하중을 전담하는 구간이 감소되는 것을 확인할 수 있다. 하지만 최대 접촉력 변화가 크지 않기 때문에 물림률을 통한 피팅수명 개선효과는 기대하기 어렵다.

또한, 동일 물림률 상황에서 전위계수가 증가되면 최대 접촉 력은 약간 증가되지만 그 변화는 크지 않음을 Fig. 11에서 알 수 있다.

Fig. 12 (a), (b)는 물림률이 각각 1.6 과 1.8 에서 전위계수 변 화에 따른 하중응력계수의 변화를 나타내고 있다. 전반적으로 전위계수가 증가함에 따라 하중응력계수는 감소하는 경향을 나타내고, 또 물림률이 낮을수록 감소폭이 증가됨을 알 수 있 다. 이는 캠 랙 치형의 형상 변경에 따른 곡률반경의 급격한

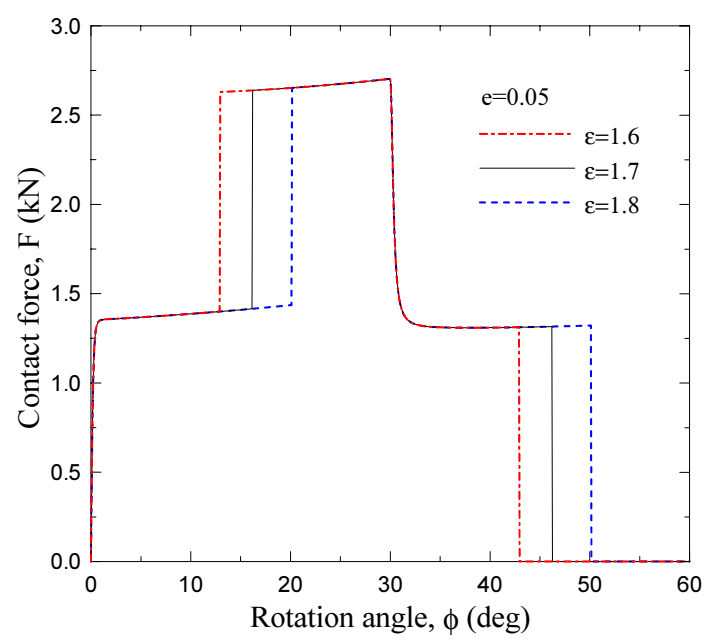

Fig. 10 Contact force with the variation of $\epsilon$

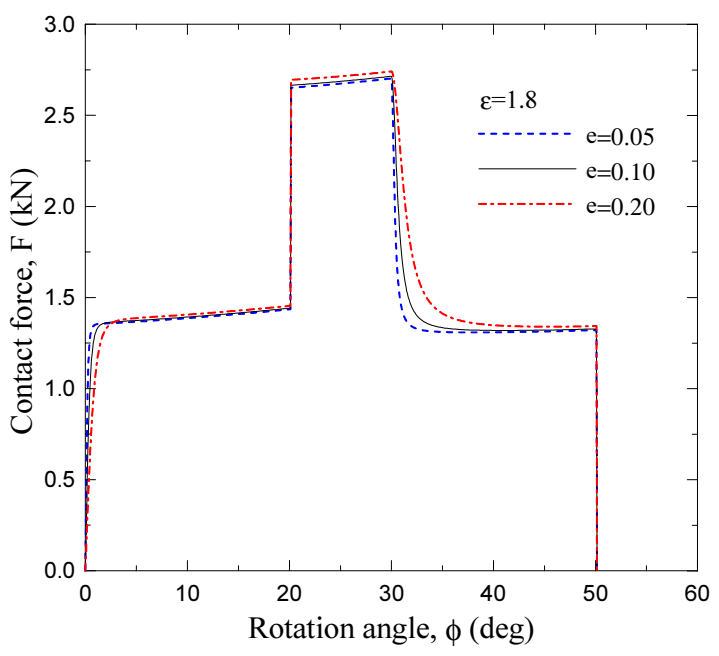

Fig. 11 Contact force with the variation of $e$ 


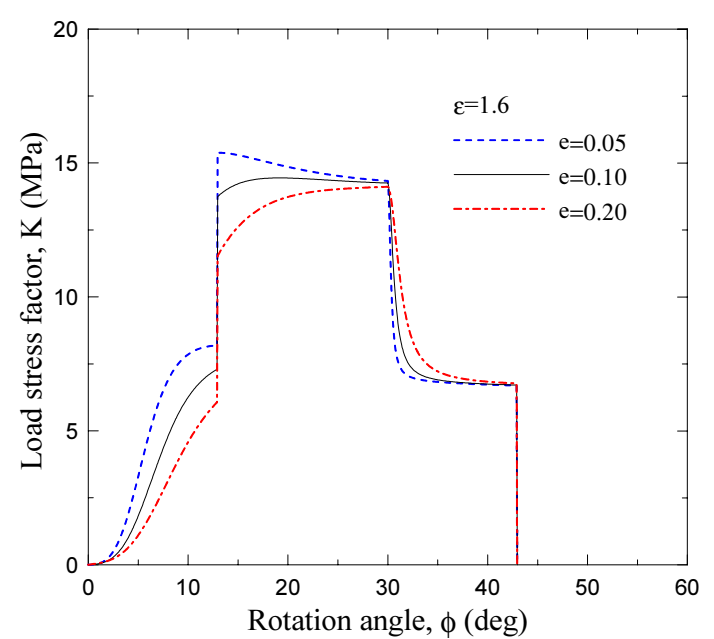

(a) $\epsilon=\mathbf{1 . 6}$

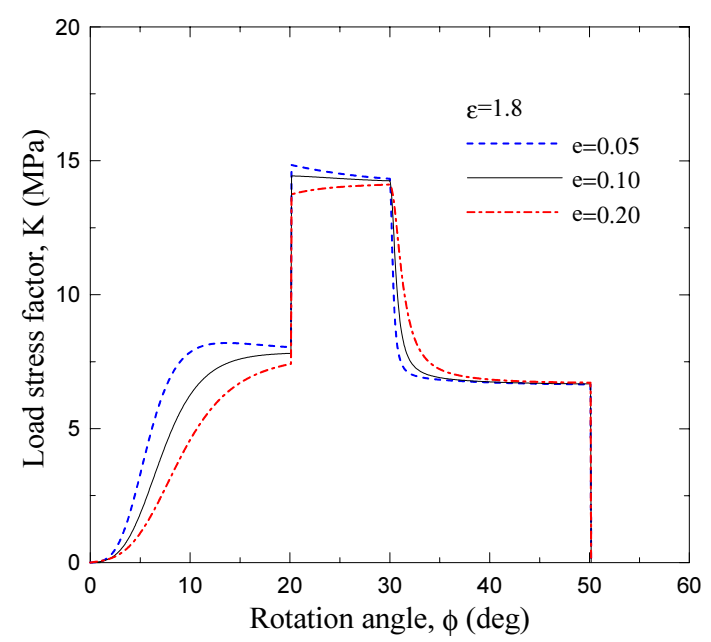

(b) $\epsilon=1.8$

Fig. 12 Load stress factor variation with $e$

Table 3 Analysis properties for surface fatigue

\begin{tabular}{c|c}
\hline \hline Properties & Material \& values \\
\cline { 1 - 2 } Cam rack & $\begin{array}{c}1020 \text { steel, HB 130-170 } \\
\text { (Phosphate coated) }\end{array}$ \\
\cline { 1 - 2 } Roller pinion & 6.38 \\
\hline$\lambda$ & 28.23 \\
\hline$\zeta$ &
\end{tabular}

Table 4 Pitting resistance with the variation of $e$

\begin{tabular}{c|c|c|c}
\hline \hline$e$ & $\left(K_{i}\right)_{\max },(\mathrm{MPa})$ & $N_{p},($ Cycles $)$ & Hrs. @120rpm \\
\hline 0.05 & 14.841 & $9.242 \times 10^{6}$ & 15403 \\
\hline 0.10 & 14.436 & $1.103 \times 10^{7}$ & 18376 \\
\hline 0.20 & 14.114 & $1.274 \times 10^{7}$ & 21228 \\
\hline
\end{tabular}

변화가 그 원인임을 알 수 있다.

Fig. 13 (a), (b)는 전위계수가 각각 0.05 와 0.20으로 고정된

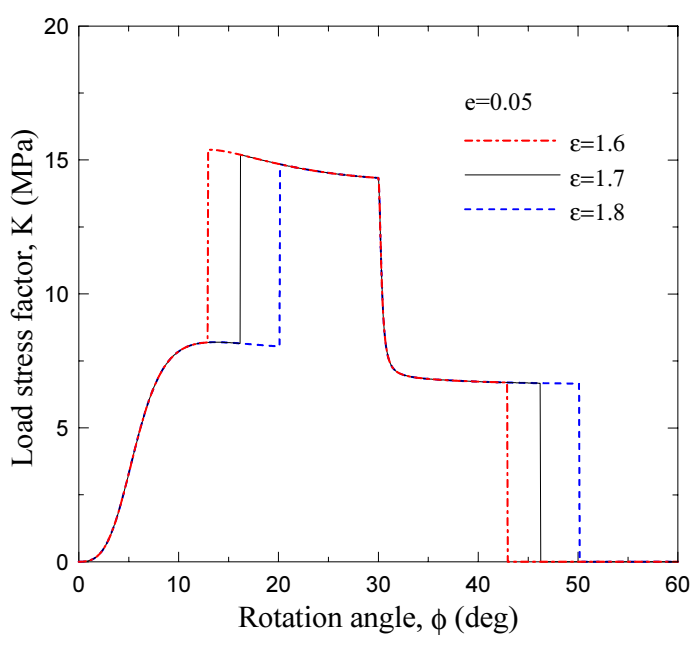

(a) $e=\mathbf{0 . 0 5}$

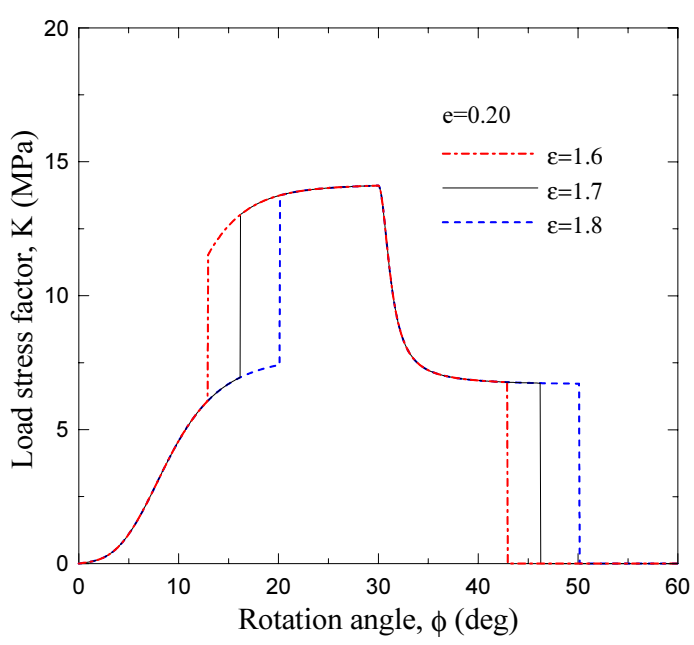

(b) $e=\mathbf{0 . 2}$

Fig. 13 Load stress factor variation with $\epsilon$

상황에서 물림률 변화에 따른 하중응력계수의 변화를 나타내 고 있다. 접촉력 해석결과에서 알 수 있듯이 롤러 1 이 이탈되는 시점을 달리할 뿐, 전반적으로 최대 하중응력계수 $\left(K_{i}\right)_{\max }$ 값의 변화는 크지 않음을 알 수 있다.

앞서 살펴 본 하중응력계수를 기반으로 CRP 시스템의 표면 피로 수명평가를 위해 Table 3과 같은 탄소강에 대한 재질 및 실험적 강도계수를 고려하였다. 이때 강도계수 $\lambda$ 및 $\zeta$ 는 일반 적인 캠 및 기어의 구름-미끄럼 조합을 반영하여 평균 $9 \%$ 의 미끄럼률을 고려한 값들이다.

물림률 $\epsilon=1.8$ 에서 식 (6)을 이용한 전위계수 변화에 따른 피팅수명 결과와 롤러 피니언의 회전수를 $120 \mathrm{rpm}$ 으로 했을 경 우의 예상수명 시간을 Table 4에 정리하였다.

전위계수가 0.20 일 때 예상 피팅발생 수명이 $1.274 \times 10^{7}$ (cycles) 로 전위계수 0.05 의 $9.242 \times 10^{6}$ (cycles)에 비해 약 $38 \%$ 연장 된 것을 알 수 있다. 
따라서 CRP 시스템에서 전체 기어 시스템 설계변수의 변화 없이 내구수명을 향상시키는 방안으로 전위계수를 증가시키는 것이 효과적일 것으로 판단된다.

\section{5. 결 론}

본 논문에서는 피니언 기어를 핀 또는 롤러로 대체한 CRP 시스템의 접촉 표면에서의 내구수명을 평가하고자 전위를 갖 는 엄밀치형을 고려하였고, 그 결과는 다음과 같다.

(1) 전위계수가 증가함에 따라 캠 랙의 치선의 폭과 치의 높이 는 감소되고, 치저 폭은 미세하게 증가되었다.

(2) 또 접촉력의 경우, 전위계수 및 물림률 변화에 따른 변화는 미미하였으나 물림률 증가 시 한 쌍의 치가 하중을 전담하 는 구간이 감소되는 것을 확인할 수 있었다.

(3) 하지만 하중응력계수는 전위계수의 증가에 따라 대체적으 로 감소하는 경향을 보이고, 물림률이 낮을수록 감소폭은 더 크게 나타남을 확인할 수 있었다.

(4) 또한 물림률에 따른 하중응력계수의 변화는 롤러 1이 이탈 되는 시점을 달리할 뿐, 최대 하중응력계수 값에는 크게 영 향을 미치지 않음을 알 수 있었다.

따라서 전위계수의 변화를 통한 치형의 설계변경은 기 설계 된 CRP 시스템에 큰 영향을 주지 않으면서 내구수명을 향상시 킬 수 있는 효과적인 방법임을 알 수 있었다.

\section{후 기}

이 연구에 참여한 연구자는 $「 2$ 단계 $\mathrm{BK} 21$ 사업」의 지원비를 받았음.

\section{참 고 문 헌}

(1) Gonzalez-Palacios, M. A., and Angeles, J., 2003, “The Design of a Novel Pure-Rolling Transmission to Convert Rotational into Translational Motion," Trans. ASME,
Jornal of Mechanism Design, Vol. 125, Issue 1, pp. 205 207.

(2) Chablat, D., and Angeles, J., 2005, "Strategies for the Design of a Slide-O-Cam Transmission," International Workshop on Computational Kinematics, pp. 1 10.

(3) Ham, S. H., Nam, W. K., and Oh, S. H., 2010, “A Study on Optimum Tooth Profile of Pin-Pinion Gear for Linear Motion," KSPSE, Vol. 14, No. 3, pp. 64 70.

(4) Imase, K., Makino, H., and Terada, H., 2000, Transmission Device for Converting a Torque between Rotary Movement and Linear Movement, US Patent: 6023989.

(5) Ikejo, K., Nagamura, K., Tanaka, E., and Yamamoto, K., 2008, "Driving Performance and Strength of Pin-Rack Gear Mechanism," Journal of Japan Society for Design Engineering, Vol. 43, No. 7, pp. 388 394.

(6) Nagamura, K., Ikejo, K., Tanaka, E., and Yamamoto, K., 2008, "Driving Performance of Pin-Rack Gear Mechanism Using a Trochoid Tooth Profile," The Machine Design and Tribology Division Meeting in JSME, pp. 205 208.

(7) Morrison, R. A., 1968, "Load/Life Curves for Gear and Cam Materials," Machine Design, Vol. 40, Aug 1, pp. 102 108.

(8) Litvin, F. L., 1994, Gear Geometry and Applied Theory, PTR Prentice Hall, Englewood Cliffs.

(9) Kwon, S. -M., Nam, H. C., Lu, L., and Shin, J. -H., 2009, "A Study on Optimal Wear Design for a Gerotor Pump," Transactions of the KSME, Series A, Vol. 33, No. 1, pp. 82 88.

(10) Kwon, S. -M., Sim, M. Y., Nam, H. C., and Shin, J. -H., 2009, "Optimal Wear Design for a Hypotrochoidal Gear Pump without Hydrodynamic Effect," Transactions of the KSME, Series A, Vol. 33, No. 12, pp. 1383 1392.

(11) Talbourdet, G. J., 1957, Surface Endurance Limits of Various USME Engineering Materials, Research Division of United Shoe Machinery Corporation, Beverly, MA. 